\title{
Prenatal and pre-weaning growth and nutrition of cattle: long- term consequences for beef production
}

\author{
P. L. Greenwood ${ }^{\dagger}$ and L. M. Cafe \\ NSW Department of Primary Industries, Beef Industry Centre of Excellence and Cooperative Research Centre for Beef Genetic Technologies, University of New \\ England, Australia
}

(Received 27 February 2007; Accepted 18 May 2007)

\begin{abstract}
Severe, chronic growth retardation of cattle early in life reduces growth potential, resulting in smaller animals at any given age. Capacity for long-term compensatory growth diminishes as the age of onset of nutritional restriction resulting in prolonged growth retardation declines. Hence, more extreme intrauterine growth retardation can result in slower growth throughout postnatal life. However, within the limits of beef production systems, neither severely restricted growth in utero nor from birth to weaning influences efficiency of nutrient utilisation later in life. Retail yield from cattle severely restricted in growth during pregnancy or from birth to weaning is reduced compared with cattle well grown early in life, when compared at the same age later in life. However, retail yield and carcass composition of low- and high-birth-weight calves are similar at the same carcass weight. At equivalent carcass weights, cattle grown slowly from birth to weaning have carcasses of similar or leaner composition than those grown rapidly. However, if high energy, concentrate feed is provided following severe growth restriction from birth to weaning, then at equivalent weights post-weaning the slowly-grown, small weaners may be fatter than their well-grown counterparts. Restricted prenatal and pre-weaning nutrition and growth do not adversely affect measures of beef quality. Similarly, bovine myofibre characteristics are little affected in the long term by growth in utero or from birth to weaning. Interactions were not evident between prenatal and pre-weaning growth for subsequent growth, efficiency, carcass, yield and beef-quality characteristics, within our pasture-based production systems. Furthermore, interactions between genotype and nutrition early in life, studied using offspring of Piedmontese and Wagyu sired cattle, were not evident for any growth, efficiency, carcass, yield and beef-quality parameters. We propose that within pasture-based production systems for beef cattle, the plasticity of the carcass tissues, particularly of muscle, allows animals that are growth-retarded early in life to attain normal composition at equivalent weights in the long term, albeit at older ages. However, the quality of nutrition during recovery from early life growth retardation may be important in determining the subsequent composition of young, light-weight cattle relative to their heavier counterparts. Finally, it should be emphasised that long-term consequences of more specific and/or acute environmental influences during specific stages of embryonic, foetal and neonatal calf development remain to be determined. This need for further research extends to consequences of nutrition and growth early in life for reproductive capacity.
\end{abstract}

Keywords: birth weight, foetal programming, meat quality, muscle fibres, neonates

\section{Introduction}

There are numerous growth path possibilities during early and later life that may influence productive characteristics of cattle. These different growth paths result from factors including climate, soil quality and pasture species, which contribute to variable pasture and nutrient quality and availability. Growth of the bovine foetus has well-studied consequences for survival (Holland and Odde, 1992) and

\footnotetext{
† E-mail: paul.greenwood@dpi.nsw.gov.au
}

can be slowed during the latter half of gestation by restricted nutrition and/or inadequate placental development (Bell et al., 2005). Similarly, influences of pre-weaning nutrition, most notably lactational performance of the dam, on growth to market weights of cattle are well characterised (Berge, 1991). However, consequences of foetal calf growth for subsequent growth, and of foetal and neonatal calf growth for efficiency and carcass- and beefquality characteristics, are less well understood.

Hence, this paper reviews research on consequences of cattle nutrition and growth during foetal and neonatal life 
for subsequent growth and efficiency, and for carcass and beef quality. It includes findings from our recent studies on consequences of maternal nutrition (commencing between days 30 and 90 of gestation) and growth during pregnancy and to weaning of cattle sired by bulls of extreme genotypes for muscle and intramuscular fat development (Cafe et al., 2006a and 2006b; Greenwood et al., 2006). Factors affecting growth and nutrition of the bovine foetus and milk-fed calf are also briefly described. The reader is also referred to reviews on consequences of prenatal development in livestock species by Bell (2006) and Symonds et al. (2007), and on consequences of bovine foetal, pre-weaning and early post-weaning growth and nutrition by Berge (1991) and Greenwood et al. (2005).

\section{Normal bovine conceptus growth and metabolism}

During postnatal growth, energy and nutrient availability directly influence growth and body composition of cattle. However, environmental influences on foetal growth and development and, hence, birth characteristics are regulated via the dam, and by the placenta that functions as a nutritional conduit between the dam and the foetus.

Most growth of the bovine foetus occurs during the final 100 days or so of a gestation averaging approximately 280 days (Winters et al., 1942; Lyne, 1960; Ferrell et al., 1976; Prior and Laster, 1979). Foetal nutrient uptake becomes a quantitatively important contributor to maternal nutrient requirements only after mid-gestation (Ferrell et al., 1983). Unlike the sheep, in which the placenta attains most of its mass of dry tissue, protein and DNA by mid-gestation (Ehrhardt and Bell, 1995), the bovine placenta normally continues to increase in weight until near term (Prior and Laster, 1979; Ferrell, 1989). As a result, it has been suggested that placental growth may be less sensitive to nutritional deficiencies in cattle than in sheep. Placental weight and birth weight are highly correlated in cattle (Anthony et al., 1986b; Echternkamp, 1993; Zhang et al., 1999); however, the functional capacity of the placenta is closely related to placental perfusion. Bovine uterine and umbilical blood flow increases exponentially during the second half of gestation, which equates to relatively constant rates of umbilical blood flow on a foetal weightspecific basis during this period (Reynolds et al., 1986). A more detailed account of placental function and metabolism in cattle is provided by Ferrell (1989), and of foetal macronutrient requirements and metabolism in cattle and sheep, and of placental function and metabolism, by Bell et al. (2005).

\section{Intrauterine growth retardation}

\section{Maternal nutrition}

Severe nutritional restriction for at least the last half to onethird of pregnancy is usually required to reduce bovine foetal growth. Significant reductions in birth weight were caused by prolonged underfeeding of heifers from weaning until parturition (Wiltbank et al., 1965), and underfeeding of heifers and cows for the second and third trimesters (Ryley and Gartner, 1962; Hodge and Rowan, 1970; Freetly et al., 2000; Cafe et al., 2006b) or late pregnancy only (Hight, 1966; Tudor, 1972; Bellows and Short, 1978; Kroker and Cummins, 1979). The effect of nutritional restriction on birth weight was more pronounced in calves from heifers than those from cows when the period of restriction encompassed mid- and late gestation (Hennessy et al., 2002) rather than late gestation only (Tudor, 1972). However, birth weight was not significantly affected by nutritional restriction of heifers from mating to 140 days gestation (Cooper et al., 1998) or during the final 12 weeks of pregnancy (Hodge et al., 1976), or of mature cows for the second trimester (Freetly et al., 2000).

During the final one-half to one-third of pregnancy, feed energy available to the dam appears to have more influence on birth weight than the availability of protein, although results are variable (Holland and Odde, 1992). Variation in feed energy available to the dam during this period resulted in differences in birth weight, ranging from 0 to $8.2 \mathrm{~kg}$ (Dunn et al., 1969; Tudor, 1972; Laster, 1974; Corah et al., 1975; Bellows and Short, 1978; Kroker and Cummins, 1979; Bellows et al., 1982). Similarly, variable protein supply of the diet during the third trimester may (Bellows et al., 1978) or may not (Anthony et al., 1986a; Holland and Odde, 1992) alter birth weight of calves, while restricted or supplemental dietary protein during early or mid-pregnancy had little effect on birth weights (Perry et al., 1999 and 2002). Furthermore, supplementation of grazing cows for 3 months pre-partum with $0.45 \mathrm{~kg} / \mathrm{day}$ of $42 \%$ crude protein supplement did not affect calf birth weights (Stalker et al., 2006). However, more chronic nutritional restriction of energy and/or protein of heifers from weaning until parturition resulted in birth weight differences of up to $10 \mathrm{~kg}$ due to energy supply and up to $7.3 \mathrm{~kg}$ due to protein supply (Wiltbank et al., 1965).

As described above, placental weight and birth weight are highly correlated in cattle. However, because the bovine placenta may continue to increase in mass until near term, it is less clear whether the placenta regulates bovine foetal growth to the same extent as it does in sheep (Ferrell, 1989). Placental characteristics may be altered by nutrition during early and mid-pregnancy without significantly affecting foetal size (Rasby et al., 1990), and protein supplementation of cows during early or mid-pregnancy may also alter placental characteristics without necessarily affecting birth weight (Perry et al., 1999 and 2002).

Development and growth of vital organs precede development of bone, muscle and fat (Palsson, 1955), respectively; hence the mass of the relatively late maturing carcass tissues are generally considered more susceptible to the effects of nutrition during later pregnancy when nutrition impacts most on foetal growth. However, more subtle effects on organ and tissue development due to nutrition during early pregnancy may occur, with the potential for 
long-term consequences for health, as shown in sheep (Greenwood and Bell, 2003; Bell et al., 2005; Symonds et al., 2007).

\section{Thermal environment}

Foetal growth in cattle was restricted $(18 \%$ lower foetal weight) by chronic heat stress of pregnant cows, while provision of shade resulted in a $3.1 \mathrm{~kg}$ increase in birth weight (Collier et al., 1982). In sheep, chronic heat stress in early to mid-gestation restricts placental development, thus imposing a limitation on subsequent foetal growth irrespective of nutrition later in pregnancy (Bell et al., 1987). This suggests that restricted foetal calf growth due to heat stress is probably a consequence of reduced placental development. Severe cold stress of cattle may also reduce foetal growth if inadequate nutrition is provided to meet the additional metabolic requirements of cows in addition to foetal requirements for growth and development (Andreoli et al., 1988), although in sheep, more moderate cold stress of ewes in late gestation increased birth weight by $15 \%$ (Thompson et al., 1982). It is believed that temperature regulates blood flow to the periphery and lungs in order to preserve or dissipate body heat, resulting in increased or decreased blood flow and nutrient supply to the gravid uterus (Reynolds et al., 1985).

\begin{abstract}
Parity
Heifers give birth to smaller calves, on average, than cows (reviewed by Holland and Odde, 1992) due at least in part to size and nutritional requirements for growth of heifers, limiting nutrient availability for placental and foetal growth. Severe maternal nutritional restriction may impact more on birth weights of calves of heifers than of cows, particularly among male calves and those of sires with inherently high birth weight of offspring (Hennessy et al., 2002), presumably due to their greater requirements for nutrients compared with female calves and those of sires with inherently low birth weight of offspring. In adolescent sheep fed to attain excessive fatness prior to and during gestation, placental and foetal growth and birth weight are reduced (Wallace et al., 1996 and 1999), although the extent to which over-nutrition of adolescent heifers influences birth weight is not clear.
\end{abstract}

\section{Litter size}

Twin calves and higher multiples are rare in cattle unless exogenous regulation of ovarian function or embryo transfer is practised. Individuals within litters have reduced foetal growth compared with singletons due to a reduced number of placentomes and mass of placenta per foetus (Hafez and Rajakoski, 1964; Greenwood et al., 2000b) and because of greater total nutrient requirements of the litter. On average, twin calves range from 7.4 to $9.8 \mathrm{~kg}$ lighter than singletons (Gregory et al., 1990 and 1996; De Rose and Wilton, 1991; Cummins, 1994; Wilkins et al., 1994).
Restricted nutrition limits foetal growth earlier and more severely in twins or higher multiples than in singletons, although stocking rates of pregnant cows fed on pasture did not significantly influence the birth weight of twins (Wilkins et al., 1994).

\section{Foetal and maternal genotype}

Foetal genotype is most important in determining foetal growth during early and mid-pregnancy, whereas maternal genotype is more important in determining foetal growth during late pregnancy when most foetal growth normally occurs and foetal growth is increasingly subject to external influences mediated via the dam. The effect of foetal and maternal genotype on foetal growth has been most convincingly demonstrated in cattle by Ferrell (1991) who implanted Charolais (heavier birth weight) or Brahman (lighter birth weight) embryos into Charolais and Brahman cows. At 232 days of pregnancy, each foetal genotype was similar in size, irrespective of dam breed. However, by 274 days of gestation Charolais foetuses in Brahman cows were $7 \mathrm{~kg}$ lighter than those in Charolais cows. In contrast, Brahman foetuses in Charolais cows were only $2 \mathrm{~kg}$ heavier than those in Brahman cows. Similar results were obtained by Joubert and Hammond (1958) for birth weights for South Devon and Dexter cattle and their reciprocal crosses. In this regard, foetal growth capacity as influenced by sex and siregenotype may also influence the nutritional status of the pregnant cow during late gestation (Greenwood et al., $2002 b)$, probably due to differences in foetal nutrient uptake, contributing to maternal nutrient requirements.

\section{Growth and development from birth to weaning}

Calves undergo a transition at birth from a diet comprising primarily glucose and amino acids to one that is quantitatively greater and is proportionately higher in fat. This is associated with maturation of the digestive, metabolic and endocrine systems. Evidence in sheep suggests severely growth-retarded newborns are immature with respect to energy metabolism and have more foetal-like metabolism than their well-grown counterparts (Greenwood et al., 2002a; Rhoads et al., 2000a and 2000b).

The major nutritional factors affecting pre-weaning calf growth and composition at weaning are the lactational performance of the dam and the quality and availability of nutrients from pasture and/or supplementation prior to and following parturition. Most notably, maternal genotype, age and parity, nutrient availability and body condition and live weight of the dam, and capacity of the calf to grow and consume milk, interact to influence lactational output. Calves become increasingly dependent on forage-based diets that result in the production of volatile fatty acids that stimulate development and maturation of the rumen (Warner and Flatt, 1965) until weaning, when this dependence becomes complete. 


\section{Long-term consequences of altered growth during the early life of cattle}

In this section, the long-term consequences of altered growth early in life for growth, feed efficiency, and carcass, yield, beef quality and myofibre characteristics are discussed first for altered foetal growth, and then for altered pre-weaning growth. Interactions between prenatal and pre-weaning growth are then discussed.

\section{Consequences of foetal growth and nutrition}

Postnatal growth. In our recent studies of consequences of foetal growth, which compared performance of calves differing by $10.2 \mathrm{~kg}$ or by $35 \%$ in birth weight (Table 1), capacity of low-birth-weight cattle to exhibit compensatory growth was limited. Cattle significantly growth retarded during foetal life due to severely restricted maternal nutrition from early pregnancy (commencing between day 30 and 90 of pregnancy) to parturition remained smaller during rearing on their dams and at any given postnatal age after weaning compared with their well-grown or betternourished counterparts (Table 1). However, it remains speculative whether this represents a permanent stunting or simply a delay of attainment of mature size of cattle. Growth of low-birth-weight cattle was significantly slower than those of high birth weight at all stages of postnatal growth, although about half the difference in average daily gain (ADG) during feedlotting was explained by differences in weight at feedlot entry between the low- and high-birthweight cattle (Table 1). However, when differences in birth weights were less-pronounced, post weaning and feedlot growth were not significantly affected by birth weight (Cafe et al., 2006a). These findings are consistent with those of Swali and Wathes (2006) who found that small size at birth resulted in smaller cattle compared with high-birth-weight cattle at 15 months of age, while average-birth-weight cattle did not differ significantly in weight during postnatal growth compared with the low- or high-birth-weight groups.

In contrast to the above findings, artificially reared lowbirth-weight male calves grew more rapidly to weaning than their high-birth-weight counterparts, although the opposite occurred for female calves (Tudor and O'Rourke, 1980). Hence, it is important to recognise that an assessment of influences of foetal development on postnatal performance requires consideration of the consequences of nutrition during pregnancy on subsequent maternal performance when offspring remain on their dams to weaning, due to carry-over effects on the dam. In this regard, readers are referred to Greenwood et al. (1998) for an example of a rearing system designed to uncouple prenatal and postnatal influences in ruminants varying in birth weight. The net effects of maternal nutrition during pregnancy on the calf remain of practical significance to livestock producers, and influences of nutrition during mid- and late pregnancy or late pregnancy only on calf weaning weight have been consistently shown (e.g. Hight, 1966 and 1968a; Cafe et al., 2006b; Stalker et al., 2006), irrespective of effects on foetal growth.

In relation to potential interactions between prenatal and postnatal nutrition and growth, differences in weight of calves at birth following three levels of maternal nutrition during late pregnancy disappeared by weaning when postnatal nutrition was of high quality and availability

Table 1 Consequences of growth in utero for growth and live-weight characteristics of beef cattle to 30 months of age (adapted from Greenwood et al., 2005 and 2006) ${ }^{+}$

\begin{tabular}{lccc}
\hline \hline & & Prenatal growth/birth weight \\
\cline { 2 - 4 } & Low $(n=120)$ & High $(n=120)$ & Significance of difference $(P)$ \\
\hline Birth weight (kg) & 28.6 & 38.8 & $<0.001$ \\
Pre-weaning ADG (g) & 670 & 759 & $<0.001$ \\
Weaning (7 months) weight (kg) & 174 & 198 & $<0.001$ \\
Backgrounding ADG (g) & 571 & 603 & $<0.001$ \\
At equivalent age (26 to 30 months) & & & $<0.001$ \\
$\quad$ Feedlot entry (26 months) weight (kg) & 481 & 520 & $<0.001$ \\
Feedlot ADG (g) & 1480 & 1617 & $<0.001$ \\
$\quad$ Feedlot exit (30 months) weight (kg) & 647 & 703 & 0.019 \\
At equivalent feedlot entry live weight (500 kg) & 797 & 715 & 0.017 \\
Age at feedlot entry (day) & & 1583 & $<0.001$ \\
Feedlot ADG (g) & 1515 & 679 & 833 \\
Feedlot exit weight (kg) & 671 & & \\
Age at feedlot exit (day) & 914 & & \\
\hline \hline
\end{tabular}

Abbreviation is: $A D G=$ average daily gain.

Values are predicted means from residual maximum likelihood (REML) analyses including effects of birth weight, pre-weaning nutrition, sex/year cohort, sire-genotype and their interactions.

${ }^{\dagger}$ Maternal nutritional treatments commenced between days 30 and 90 of pregnancy (refer to Cafe et al. (2006b) and Greenwood et al. (2006) for details of pasture-based nutritional treatments and selection criteria for calves used to study long-term consequences of growth early in life).

${ }^{\ddagger}$ Predicted from mean ADG during backgrounding.

${ }^{\S}$ Predicted from mean ADG during background and mean feedlotting period. 
Table 2 Consequences of growth in utero for feed intake and efficiency of beef cattle during feedlotting from 26 to 30 months of age (L. M. Cafe and P. L. Greenwood, unpublished results)

\begin{tabular}{|c|c|c|c|}
\hline & \multicolumn{3}{|c|}{ Prenatal growth/birth weight } \\
\hline & Low $(n=77)$ & High $(n=77)$ & Significance of difference $(P)$ \\
\hline Birth weight $(\mathrm{kg})$ & 28.1 & 38.4 & \\
\hline \multicolumn{4}{|l|}{ At equivalent age (26 to 30 months) } \\
\hline Feedlot entry (26 months) weight $(\mathrm{kg})$ & 466 & 513 & $<0.001$ \\
\hline Feedlot ADG $(g)^{\dagger}$ & 1279 & 1396 & 0.004 \\
\hline Feed intake $(\mathrm{kg} / \mathrm{day})^{\dagger}$ & 13.21 & 14.63 & $<0.001$ \\
\hline Feed efficiency (kg DM intake/kg LW gain) & 10.00 & 10.38 & 0.26 \\
\hline Residual feed intake $(\mathrm{kg})^{\ddagger}$ & -0.005 & 0.003 & 0.99 \\
\hline \multicolumn{4}{|l|}{ At equivalent feedlot entry $\mathrm{LW}(490 \mathrm{~kg})$} \\
\hline Feedlot ADG $(g)^{\dagger}$ & 1317 & 1361 & 0.46 \\
\hline Feed intake $(\mathrm{kg} / \mathrm{day})^{\dagger}$ & 13.86 & 14.01 & 0.55 \\
\hline Feed efficiency (kg DM intake/kg LW gain) & 10.25 & 10.15 & 0.89 \\
\hline
\end{tabular}

Abbreviations are: $A D G=$ average daily gain, $D M=$ dry matter; $L W=$ live weight.

Values are predicted means from residual maximum likelihood (REML) analyses including effects of birth weight, pre-weaning nutrition, sex/year cohort, sire-genotype and their interactions, with feedlot entry weight as a covariate (linear and, where significant, quadratic) to predict means at equivalent feedlot entry weight. Difference in significance of feedlot ADG between Tables 1 and 2 is due to the number of cohorts studied (three cohorts in Table $1 \mathrm{v}$. two cohorts in Table 2) and the duration of the measurement period (average of 117 days in Table $1 v$. 70 days in Table 2).

${ }^{+}$During 70-day period in feed intake pens.

${ }^{\ddagger}$ At mean metabolic live weight.

(Hight, 1968b). In this study, however, residual effects of the previous year's nutrition influenced calf growth, with cows previously well nourished producing heavier calves, and vice versa (Hight, 1968b). Similarly, effects of variable nutrition during mid- and/or late pregnancy on weight at birth were overcome by adequate nutrition post partum, resulting in no difference in body weight at 58 days of age (Freetly et al., 2000). While twin cattle are lighter at birth and grow more slowly on their dams to weaning (Hennessy and Wilkins, 1997), they may grow more slowly (Gregory et al., 1996), at a similar rate (De Rose and Wilton, 1991) or more rapidly (Wilkins et al., 1994; Clarke et al., 1994; Hennessy and Wilkins, 1997) post-weaning than singletons, depending on the rearing system and subsequent nutritional regimen.

Feed intake and efficiency. Slower feedlot growth by lowbirth-weight calves was associated with the consumption of fewer nutrients in the feedlot but no difference in feed efficiency or residual feed intake compared with high-birthweight calves at an equivalent age from 26 to 30 months (Table 2). When compared at equivalent feedlot entry live weights, differences in feed intake due to birth weight were no longer apparent, consistent with findings in twin cattle, which tended to consume less feed in feedlot than singletons, due primarily to their lower live weight (De Rose and Wilton, 1991). Similarly, provision of supplement to cows for 3 months pre-partum had no significant post-weaning effects on $A D G$, feed intake and feed efficiency in steers (Stalker et al., 2006) or heifers (Martin et al., 2007) that were individually fed following weaning, although the heifers of supplemented cows tended to have greater absolute and residual feed intakes during individual feeding for 84 days post-weaning.
Body and carcass composition. Few studies have examined long-term consequences of foetal nutrition and growth for body and carcass characteristics in cattle (Tudor et al., 1980) prior to our more recent studies (Greenwood et al., 2006). Our research has shown that a significant reduction in birth weight following severe maternal nutritional restriction did not influence indices of fatness, apart from P8 (rump) fat, in carcasses of Wagyu- or Piedmontese-sired steers and heifers at 30 months of age, beyond that normally attributable to differences in live or carcass weight (Table 3). Low-birth-weight cattle had a similar intramuscular fat content, retail yield, fat trim and bone content at equivalent carcass weight, suggesting little overall difference in carcass composition from their high-birth-weight counterparts. However, ossification score was higher in low- compared with high-birth-weight calves (Table 3), suggesting an impact of prenatal growth on calcification of bone and relative maturity. Similar to our findings, gross compositional differences were not evident in the whole body or in the carcass of Hereford steers or heifers grown to 370 to $400 \mathrm{~kg}$ live weight following restricted or adequate nutrition of their dams from 180 days of pregnancy to parturition with a resultant $22 \%$ or $6.8 \mathrm{~kg}$ difference in calf birth weight (Tudor et al., 1980). Furthermore, pre-partum supplementation of cows had no effects on the carcass composition of offspring following feedlotting for 222 days post weaning (Stalker et al., 2006).

Research on twin cattle has also demonstrated that, despite significantly lower birth weights and reduced preweaning growth, compositional differences at equivalent slaughter weights or ages are small and not significant, with twins generally having similar or leaner carcasses than singletons (De Rose and Wilton, 1991; Wilkins et al., 1994; Clarke et al., 1994; Gregory et al., 1996). 
Table 3 Consequences of growth in utero for carcass and yield characteristics of beef cattle at 30 months of age (adapted from Greenwood et al., 2006)

\begin{tabular}{|c|c|c|c|}
\hline & \multicolumn{3}{|c|}{ Prenatal growth/birth weight } \\
\hline & Low $(n=120)$ & High $(n=120)$ & Significance of difference $(P)$ \\
\hline \multicolumn{4}{|c|}{ At equivalent age (30 months) } \\
\hline Carcass weight $(\mathrm{kg})$ & 364 & 396 & $<0.001$ \\
\hline Retail yield $(\mathrm{kg})$ & 239 & 257 & $<0.001$ \\
\hline \multicolumn{4}{|c|}{ At equivalent carcass weight $(380 \mathrm{~kg})$} \\
\hline Eye muscle area $\left(\mathrm{cm}^{2}\right)$ & 90.4 & 88.9 & 0.25 \\
\hline P8 fat depth (mm) & 21.3 & 19.6 & 0.048 \\
\hline Rib fat depth (mm) & 10.9 & 10.5 & 0.35 \\
\hline Aus-Meat marble score & 1.83 & 1.86 & 0.56 \\
\hline USDA marble score & 447 & 444 & 0.98 \\
\hline Longissimus IMF (\%) & 6.8 & 7.0 & 0.62 \\
\hline Ossification score & 206 & 195 & 0.009 \\
\hline Retail yield $(\mathrm{kg})$ & 249 & 247 & 0.20 \\
\hline Bone $(\mathrm{kg})$ & 66.9 & 67.6 & 0.10 \\
\hline Fat trim $(\mathrm{kg})$ & 54.6 & 56.0 & 0.58 \\
\hline
\end{tabular}

Abbreviation is: IMF = intramuscular fat.

Values are predicted means from residual maximum likelihood (REML) analyses including effects of birth weight, pre-weaning nutrition, sex/year cohort, siregenotype and their interactions, with carcass weight as a covariate (linear and, where significant, quadratic) to predict means at equivalent carcass weight. Refer to Table 1 for growth characteristics of the cattle.

Table 4 Consequences of growth in utero for objective measurements of $\mathrm{m}$. longissimus (striploin) and $\mathrm{m}$. semitendinosus (eye round) quality in beef cattle at 30 months of age (adapted from Greenwood et al., 2006)

\begin{tabular}{|c|c|c|c|}
\hline & \multicolumn{3}{|c|}{ Prenatal growth/birth weight } \\
\hline & Low $(n=120)$ & High $(n=120)$ & Significance of difference $(P)$ \\
\hline \multicolumn{4}{|l|}{ Longissimus } \\
\hline Peak force $(\mathrm{N})^{\dagger}$ & 39.2 & 40.5 & 0.26 \\
\hline Compression $(\mathrm{N})^{\dagger}$ & 13.9 & 14.4 & 0.19 \\
\hline Cooking loss (\%) & 21.6 & 21.7 & 0.57 \\
\hline Ultimate $\mathrm{pH}$ & 5.47 & 5.48 & 0.50 \\
\hline Colour L (lightness) & 39.5 & 40.0 & 0.21 \\
\hline Colour a (red/green) & 26.3 & 26.7 & 0.20 \\
\hline Colour b (yellow/blue) & 13.6 & 13.8 & 0.15 \\
\hline \multicolumn{4}{|l|}{ Semitendinosus } \\
\hline Peak force $(\mathrm{N})^{\dagger}$ & 46.2 & 46.4 & 0.81 \\
\hline Compression $(\mathrm{N})^{\dagger}$ & 22.6 & 22.7 & 0.97 \\
\hline Cooking loss (\%) & 21.5 & 21.3 & 0.52 \\
\hline
\end{tabular}

Values are predicted means from residual maximum likelihood (REML) analyses including effects of birth weight, pre-weaning nutrition, sex, sire-genotype and their interactions. Refer to Tables 1 and 3 for growth and carcass characteristics of the cattle.

${ }^{\dagger}$ Objective measures of texture, as defined by Perry et al. (2001).

Beef quality and myofibre characteristics. There were no adverse effects on objective measurements of beef quality including peak force, compression, cooking loss and colour in the longissimus (striploin) and semitendinosus (eye round) muscles at 30 months of age due to restricted growth in utero (Table 4).

Myofibre characteristics including number and size of myofibres, and percentages and relative areas of myofibres in the $\mathrm{m}$. longissimus lumborum (Table 5 ) and semitendinosus (results not shown) muscles at 30 months of age, were also unaffected by calf growth in utero (Table 5).
In this regard, nutrition during pregnancy resulting in divergent foetal calf growth resulted in differences at birth in the percentages of type 1 (low $17.2 \mathrm{v}$. high 23.3\%) and type $2 \mathrm{~A}(28.2 \mathrm{v} .23 .5 \%)$ myofibres, the ratio of fast to slow (4.8 v. 3.4) myofibres and the cross-sectional area of type 2X (673 v. $831 \mu \mathrm{m}^{2}$ ) myofibres (Greenwood et al., 2004). However, differences in myofibre characteristics due to foetal growth were no longer evident by weaning (P. L. Greenwood, unpublished results). Within the present study, as with newborn lambs restricted in growth during mid- to late pregnancy (Greenwood et al., 1999 and 2000a), 
Table 5 Consequences of growth in utero for longissimus lumborum myofibre characteristics of heifer beef cattle at 30 months of age (P. L. Greenwood and L. M. Café, unpublished results)

\begin{tabular}{|c|c|c|c|}
\hline & & Prenatal growt & \\
\hline & Low $(n=38)$ & High $(n=40)$ & Significance of difference $(P)$ \\
\hline Birth weight $(\mathrm{kg})$ & 27.3 & 35.9 & \\
\hline Live weight at 30 months $(\mathrm{kg})$ & 594 & 655 & $<0.001$ \\
\hline Carcass weight $(\mathrm{kg})$ & 335 & 370 & $<0.001$ \\
\hline Muscle weight $(\mathrm{g})$ & 4097 & 4453 & 0.002 \\
\hline Muscle CSA $\left(\mathrm{cm}^{2}\right)$ & 85.3 & 90.4 & 0.029 \\
\hline Myofibres per $\mathrm{mm}^{2}$ & 130.5 & 126.8 & 0.62 \\
\hline Apparent myofibre number $\left(\times 10^{-6}\right)$ & 1.112 & 1.137 & 0.78 \\
\hline Average myofibre CSA $\left(\mu \mathrm{m}^{2}\right)$ & 5708 & 5731 & 0.86 \\
\hline Total myofibre area (\%) & & & \\
\hline Type 1 & 22.5 & 22.5 & 0.99 \\
\hline Type $2 \mathrm{C}$ & 0.55 & 0.71 & 0.52 \\
\hline Type $2 \mathrm{~A}$ & 21.9 & 23.4 & 0.43 \\
\hline Type $2 A X$ & 5.61 & 6.27 & 0.53 \\
\hline Type $2 X$ & 49.5 & 47.2 & 0.44 \\
\hline
\end{tabular}

Abbreviation is: CSA = cross-sectional area.

Values are predicted means from residual maximum likelihood (REML) analyses including effects of birth weight, pre-weaning nutrition, sex, sire-genotype and their interactions.

Refer to Lehnert et al. (2006) for myofibre classification and measurement methodology. Type 1, type 1 myosin heavy chain (MHC) $\equiv$ slow oxidative; type $2 \mathrm{C}$, intermediate between type 1 and type $2 A$; type $2 A$, type $2 \mathrm{~A} \mathrm{MHC} \equiv$ fast oxidative-glycolytic; type $2 \mathrm{AX}$, intermediate between type $2 \mathrm{~A}$ and type $2 \mathrm{X}$; type $2 \mathrm{X}$, type $2 \mathrm{X} \mathrm{MHC} \equiv$ fast glycolytic.

apparent myofibre number was not affected by divergent growth in utero (Table 5).

\section{Consequences of pre-weaning growth and nutrition}

Postnatal growth. Consequences of nutritional restriction from birth to weaning for subsequent growth of cattle were reviewed by Allden (1970), Berge (1991) and Hearnshaw (1997). It is generally recognised that severe pre-weaning nutritional restriction limits the capacity of cattle to exhibit compensatory growth and achieve equivalent weight for age in later life. In reviewing a series of Australian studies on consequences of pre-weaning nutritional systems, Hearnshaw (1997) concluded that compensatory gain following pre-weaning growth restriction occurred most frequently when overall post-weaning growth rates were less than $0.6 \mathrm{~kg} / \mathrm{day}$, whereas at higher post-weaning growth rates compensation was less evident. However, in feedlot the differences in growth were in the opposite direction to differences in growth post-weaning, and when compensation did occur among cattle restricted prior to weaning, the gains were only small. In more recent studies, calves reared slowly $(464 \mathrm{~g} /$ day) compared with those reared rapidly ( $872 \mathrm{~g} /$ day) from birth to weaning were $37 \mathrm{~kg}$ lighter at weaning, but $48 \mathrm{~kg}$ lighter following backgrounding due to a trend towards slower backgrounding growth among the previously restricted cattle, and remained $46 \mathrm{~kg}$ lighter at slaughter at 17 months of age (Hennessy and Morris, 2003; Hennessy and Arthur, 2004).

In our recent studies, a difference in weaning weight of $73 \mathrm{~kg}$ resulted in a $40 \mathrm{~kg}$ difference in live weight and $24 \mathrm{~kg}$ in carcass weight at 30 months of age (Greenwood et al.,
2005 and 2006; Table 6). The low weaning weight cattle grew more rapidly during backgrounding and at a similar rate in the feedlot, resulting in more rapid growth overall from weaning to 30 months of age. However, compensation in live weight remained incomplete by the conclusion of the study. Similarly, in steers restricted in growth from birth to weaning, then backgrounded to the same feedlot entry weight as cattle grown rapidly to weaning, some compensatory growth was observed during backgrounding but not in the feedlot (Cafe et al., 2006a). These studies have confirmed earlier findings that severe, chronic nutritional restriction to weaning limits compensatory growth, which only occurred prior to feedlot entry and not in the feedlot, resulting in smaller cattle and carcasses and less retail yield of beef at an equivalent age.

Feed intake and efficiency. During feedlotting from 26 to 30 months of age, feed intake was lower among cattle grown slowly to weaning than those grown rapidly; however, this effect of pre-weaning growth rate was not evident when assessed at the same feedlot entry weight (Table 7). Differences in feed efficiency or residual feed intake were not apparent on an age- or live-weight equivalent basis. Consistent with these findings, when variation in live weight that contributed to differences in energy requirements for maintenance and growth were accounted for, low pre-weaning growth rates did not influence measures of efficiency in the feedlot of cattle of equivalent age compared with those grown more rapidly prior to weaning (Hennessy and Arthur, 2004). Furthermore, effects of early post partum nutrition on growth, intake and efficiency of 
Table 6 Consequences of growth from birth to weaning for growth and live weight characteristics of beef cattle to 30 months of age (adapted from Greenwood et al., 2005 and 2006) ${ }^{+}$

\begin{tabular}{|c|c|c|c|}
\hline & \multicolumn{3}{|c|}{ Pre-weaning growth } \\
\hline & Low $(n=119)$ & High $(n=121)$ & Significance of difference $(P)$ \\
\hline Birth weight $(\mathrm{kg})$ & 33.1 & 34.2 & \\
\hline Pre-weaning ADG (g) & 554 & 875 & \\
\hline Weaning (7 months) weight $(\mathrm{kg})$ & 151 & 221 & \\
\hline Backgrounding ADG (g) & 615 & 558 & $<0.001$ \\
\hline \multicolumn{4}{|l|}{ At equivalent age ( 26 to 30 months) } \\
\hline Feedlot entry (26 months) weight $(\mathrm{kg})$ & 483 & 517 & $<0.001$ \\
\hline Feedlot ADG (g) & 1527 & 1570 & 0.15 \\
\hline Feedlot exit (30 months) weight $(\mathrm{kg})$ & 655 & 695 & $<0.001$ \\
\hline \multicolumn{4}{|c|}{ At equivalent feedlot entry live weight $(500 \mathrm{~kg})$} \\
\hline Age at feedlot entry (day) $)^{\ddagger}$ & 789 & 724 & $<0.001$ \\
\hline Feedlot ADG $(\mathrm{g})$ & 1558 & 1540 & 0.49 \\
\hline Feedlot exit weight $(\mathrm{kg})$ & 674 & 676 & 0.52 \\
\hline Age at feedlot exit (day) ${ }^{\S}$ & 907 & 841 & $<0.001$ \\
\hline
\end{tabular}

Abbreviation is: $A D G=$ average daily gain.

Values are predicted means from residual maximum likelihood (REML) analyses including effects of birth weight, pre-weaning nutrition, sex/year cohort, siregenotype and their interactions, with feedlot entry weight as a covariate (linear and, where significant, quadratic) to predict means at equivalent feedlot entry weight.

${ }^{\dagger}$ Refer to Cafe et al. (2006b) and Greenwood et al. (2006) for details of pasture-based nutritional treatments and selection criteria for calves used to study long-term consequences of growth early in life.

${ }^{\ddagger}$ Predicted from mean ADG during backgrounding.

$\S$ Predicted from mean ADG during background and mean feedlotting period.

Table 7 Consequences of growth from birth to weaning for feed intake and efficiency of beef cattle during feedlotting from 26 to 30 months of age (L. M. Cafe and P. L. Greenwood, unpublished results)

\begin{tabular}{|c|c|c|c|}
\hline & \multicolumn{3}{|c|}{ Pre-weaning growth } \\
\hline & Low $(n=75)$ & High $(n=79)$ & Significance of difference $(P)$ \\
\hline Weaning weight $(\mathrm{kg})$ & 149 & 215 & \\
\hline \multicolumn{4}{|l|}{ At equivalent age (26-30 months) } \\
\hline Feedlot entry (26 months) weight (kg) & 477 & 502 & $<0.001$ \\
\hline Feedlot $A D G(g)^{\dagger}$ & 1319 & 1356 & 0.36 \\
\hline Feed intake $(\mathrm{kg} / \text { day })^{\dagger}$ & 13.59 & 14.24 & 0.002 \\
\hline Feed efficiency (kg DM intake/kg LW gain) & 10.02 & 10.36 & 0.33 \\
\hline Residual feed intake $(\mathrm{kg})^{\ddagger}$ & -0.042 & 0.040 & 0.51 \\
\hline \multicolumn{4}{|l|}{ At equivalent feedlot entry LW $(490 \mathrm{~kg})$} \\
\hline Feedlot ADG $(\mathrm{g})^{+}$ & 1317 & 1361 & 0.94 \\
\hline Feed intake $(\mathrm{kg} / \text { day })^{\dagger}$ & 13.89 & 13.98 & 0.55 \\
\hline Feed efficiency (kg DM intake/kg LW gain) & 10.13 & 10.27 & 0.66 \\
\hline
\end{tabular}

Abbreviations are: $A D G=$ average daily gain, $D M=$ dry matter, $L W=$ live weight.

Values are predicted means from residual maximum likelihood (REML) analyses including effects of birth weight, pre-weaning nutrition, sex/year cohort, siregenotype and their interactions, with feedlot entry weight as a covariate (linear and, where significant, quadratic) to predict means at equivalent feedlot entry weight. Difference in significance of feedlot ADG between Tables 6 and 7 is due to the number of cohorts studied (three in Table $6 \mathrm{v}$. two in Table 7) and the duration of the measurement period (average of 117 days in Table 6 v. 70 days in Table 7).

${ }^{\dagger}$ During 70 -day period in feed intake pens.

${ }^{\ddagger}$ At mean metabolic live weight.

steers (Stalker et al., 2006) and heifers (Martin et al., 2007) in the feedlot soon after weaning were not evident. These results are consistent with earlier findings, reviewed by Berge (1991), that feed conversion efficiency is little affected in the long term by nutrition prior to weaning. However, following extremely severe postnatal nutritional restriction where calves were held near their birth weights for 200 days, compared with cattle well grown to weaning, feed efficiency was adversely affected in males during growth from $200 \mathrm{~kg}$ to about $400 \mathrm{~kg}$ live weight, whereas during the same period females were more efficient (Tudor and O'Rourke, 1980).

Body and carcass composition. At equivalent carcass weight, there was more fat trim, less retail yield and there 
Table 8 Consequences of growth from birth to weaning for carcass characteristics of beef cattle at 30 months of age (adapted from Greenwood et al., 2006)

\begin{tabular}{|c|c|c|c|}
\hline & \multicolumn{3}{|c|}{ Pre-weaning growth } \\
\hline & Low $(n=119)$ & High $(n=121)$ & Significance of difference $(P)$ \\
\hline \multicolumn{4}{|c|}{ At equivalent age (30 months) } \\
\hline Carcass weight $(\mathrm{kg})$ & 368 & 393 & $<0.001$ \\
\hline Retail yield $(\mathrm{kg})$ & 242 & 254 & $<0.001$ \\
\hline \multicolumn{4}{|c|}{ At equivalent carcass weight $(380 \mathrm{~kg})$} \\
\hline Eye muscle area $\left(\mathrm{cm}^{2}\right)$ & 90.1 & 89.2 & 0.55 \\
\hline P8 fat depth (mm) & 20.1 & 20.8 & 0.41 \\
\hline Rib fat depth (mm) & 10.4 & 11.0 & 0.33 \\
\hline Aus-Meat marble score & 1.92 & 1.77 & 0.15 \\
\hline USDA marble score & 450 & 441 & 0.49 \\
\hline Longissimus IMF (\%) & 6.88 & 6.98 & 0.80 \\
\hline Ossification score & 202 & 199 & 0.53 \\
\hline Retail yield $(\mathrm{kg})$ & 251 & 246 & $<0.001$ \\
\hline Bone (kg) & 67.8 & 66.7 & 0.053 \\
\hline Fat trim $(\mathrm{kg})$ & 52.8 & 57.8 & $<0.001$ \\
\hline
\end{tabular}

Abbreviation is: IMF = intramuscular fat.

Values are predicted means from residual maximum likelihood (REML) analyses including effects of birth weight, pre-weaning nutrition, sex/year cohort, siregenotype and their interactions, with carcass weight as a covariate (linear and, where significant, quadratic) to predict means at equivalent carcass weight. Refer to Table 6 for growth characteristics of the cattle.

tended to be less bone in the carcass among the cattle grown rapidly compared with those grown slowly to weaning (Greenwood et al., 2006; Table 8). This suggests the greater fatness at weaning of the rapidly reared cattle persisted to 30 months of age. However, because of failure to compensate fully in weight, the carcasses from light weaners remained smaller and weight of retail beef was lower compared with the heavy weaners at the same age. When cattle grown rapidly or slowly to weaning were backgrounded to the same feedlot entry weight and slaughtered after 120 days in the feedlot, their carcasses did not differ in compositional and yield characteristics (Cafe et al., 2006a).

Earlier studies within pasture-based nutritional systems also failed to demonstrate substantial differences in body or carcass composition due to nutrition and growth from birth to weaning (Berge, 1991; Hearnshaw, 1997). These authors concluded that cattle from low pre-weaning nutrition groups generally have less fat than those from high preweaning nutrition groups, but if compared at a constant carcass weight, differences in fatness usually disappear. As a result, calves with lower weaning weights take longer to reach carcass specifications than heavier calves.

In contrast to the above findings, severe nutritional restriction to weaning that resulted in little growth post partum, followed by concentrate (high energy) feeding from weaning to slaughter resulted in greater fatness at the same live and carcass weights compared with cattle well nourished prior to weaning (Tudor et al., 1980). Within the same study, cattle restricted or well nourished to weaning then grown on pasture to the same slaughter weight did not differ in composition. Factors likely to have contributed to increased fatness among the small compared with large weaners, which were subsequently fed concentrates, include the following: greater length of time on concentrate feed to reach the slaughter weight; greater weight-specific intake of nutrients following the nutritional restriction; a greater requirement for protein relative to energy at weaning and, hence, potential nutrient imbalance in the concentrate diet during the early post-weaning phase; and more limited capacity for lean tissue accretion post weaning in the small compared with large weaners.

Beef quality and myofibre characteristics. Differences in objective measurements of meat quality between cattle grown slowly or rapidly to weaning were not evident within our research (Greenwood et al., 2006; Table 9). Similarly, in earlier studies, objective measures of eating quality were not adversely affected by restricted nutrition prior to weaning (Hearnshaw, 1997; Hennessy et al., 2001; Hennessy and Morris, 2003). When they were affected, however, meat of cattle from low-nutrition groups was usually more tender than that of high-nutrition groups (Hearnshaw, 1997; Hennessy et al., 2001). However, when compared at a constant carcass weight, in about half of the studies the meat quality differences became non-significant (Hearnshaw, 1997). Despite these findings, meat quality may be compromised if the slow growth of cattle alter weaning results in them being at least 8 to 9 months older at slaughter weight (Loxton, 1997; Purchas et al., 2002). It is unclear if similar age differences resulting from growth restriction earlier in life have similar effects.

As with the above findings for meat quality, growth to weaning had little overall affect on myofibre characteristics in the longissimus lumborum muscle at 30 months of age, apart from a small increase in the relative area of type 1 
Table 9 Consequences of growth from birth to weaning for objective measurements of $\mathrm{m}$. longissimus (striploin) and $\mathrm{m}$. semitendinosus (eye round) quality in beef cattle at 30 months of age (adapted from Greenwood et al., 2006)

\begin{tabular}{|c|c|c|c|}
\hline & \multicolumn{3}{|c|}{ Pre-weaning growth } \\
\hline & Low $(n=119)$ & High $(n=121)$ & Significance of difference $(P)$ \\
\hline \multicolumn{4}{|l|}{ Longissimus } \\
\hline Peak force $(N)^{\dagger}$ & 40.5 & 39.2 & 0.25 \\
\hline Compression $(\mathrm{N})^{+}$ & 14.2 & 14.1 & 0.63 \\
\hline Cooking loss (\%) & 21.8 & 21.5 & 0.23 \\
\hline Ultimate $\mathrm{pH}$ & 5.48 & 5.47 & 0.60 \\
\hline Colour L (lightness) & 39.9 & 39.6 & 0.48 \\
\hline Colour a (red/green) & 26.5 & 26.6 & 0.70 \\
\hline Colour b (yellow/blue) & 13.7 & 13.7 & 0.93 \\
\hline \multicolumn{4}{|l|}{ Semitendinosus } \\
\hline Peak force $(\mathrm{N})^{\dagger}$ & 46.3 & 46.3 & 0.89 \\
\hline Compression $(\mathrm{N})^{+}$ & 22.1 & 22.8 & 0.47 \\
\hline Cooking loss (\%) & 21.5 & 21.3 & 0.45 \\
\hline
\end{tabular}

Values are predicted means from residual maximum likelihood (REML) analyses including effects of birth weight, pre-weaning nutrition, sex, sire-genotype and their interactions. Refer to Tables 6 and 8 for growth and carcass characteristics of the cattle.

${ }^{\dagger}$ Objective measures of texture, as defined by Perry et al. (2001).

Table 10 Consequences of growth from birth to weaning for longissimus lumborum myofibre characteristics of heifer beef cattle at 30 months of age (P. L. Greenwood and L. M. Cafe, unpublished results)

\begin{tabular}{|c|c|c|c|}
\hline & \multicolumn{3}{|c|}{ Pre-weaning growth } \\
\hline & Low $(n=40)$ & High $(n=38)$ & Significance of difference $(P)$ \\
\hline Weaning weight $(\mathrm{kg})$ & 138 & 203 & \\
\hline Live weight at 30 months $(\mathrm{kg})$ & 612 & 637 & 0.025 \\
\hline Carcass weight $(\mathrm{kg})$ & 345 & 360 & 0.032 \\
\hline Muscle weight $(\mathrm{g})$ & 4191 & 4358 & 0.14 \\
\hline Muscle CSA $\left(\mathrm{cm}^{2}\right)$ & 87.3 & 88.4 & 0.58 \\
\hline Myofibres per $\mathrm{mm}^{2}$ & 132.9 & 124.4 & 0.27 \\
\hline Average myofibre CSA $\left(\mu \mathrm{m}^{2}\right)$ & 5585 & 5854 & 0.32 \\
\hline \multicolumn{4}{|l|}{ Total myofibre area $(\%)$} \\
\hline Type 1 & 23.9 & 21.1 & 0.017 \\
\hline Type 2C & 0.59 & 0.67 & 0.75 \\
\hline Type $2 \mathrm{~A}$ & 22.6 & 22.7 & 0.89 \\
\hline Type $2 A X$ & 6.58 & 5.30 & 0.28 \\
\hline Type $2 X$ & 46.4 & 50.2 & 0.24 \\
\hline
\end{tabular}

Abbreviation is: CSA $=$ cross-sectional area.

Values are predicted means from residual maximum likelihood (REML) analyses including effects of birth weight, pre-weaning nutrition, sex, sire-genotype and their interactions. Refer to Lehnert et al. (2006) for myofibre classification and measurement methodology. Type 1, type 1 myosin heavy chain (MHC) $\equiv$ slow oxidative; Type $2 \mathrm{C}$, intermediate between type 1 and type $2 \mathrm{~A}$; Type $2 \mathrm{~A}$, type $2 \mathrm{~A} M \mathrm{MHC} \equiv$ fast oxidative-glycolytic; Type $2 \mathrm{AX}$, intermediate between type $2 \mathrm{~A}$ and

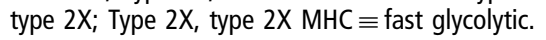

myofibres in cattle grown slowly to weaning compared with those grown rapidly (Table 10). This is despite differences due to pre-weaning growth in the size of each myofibre type and the percentages and relative area of fast (type 2) myofibres at weaning (P. L. Greenwood, unpublished results).

\section{Interactions between in utero and pre-weaning growth}

Among the numerous beef production characteristics that we investigated, the only interaction between growth in utero and growth prior to weaning was for the eye muscle ( $m$. longissimus) cross-sectional area when compared at an equivalent carcass weight at 30 months of age (Greenwood et al., 2006). Cattle of low birth weight had a greater eye muscle area at slaughter than high-birth-weight cattle within the high pre-weaning growth group (91.1 v . $87.2 \mathrm{~cm}^{2}$ ), suggesting, perhaps, in conjunction with the results for subcutaneous fat depth, some long-term consequences of divergent foetal growth for distribution of carcass tissues. However, the eye muscle area did not differ due to birth weight within the animals that grew slowly to weaning (89.8 v. $90.5 \mathrm{~cm}^{2}$, respectively). Similarly, interactions between prenatal and pre-weaning nutrition for 
post-weaning growth, feed intake, feed efficiency and carcass characteristics were not evident in the study of Stalker et al. (2006).

\section{Interactions between growth early in life and gender}

There appear to be few studies of interactions between growth early in life and the gender of cattle on beef production characteristics. Growth of well nourished, artificially reared calves (Tudor and O'Rourke, 1980) and feed efficiency after weaning have been shown to be influenced by gender following maternal nutritional restriction (Tudor and O'Rourke, 1980). The results of Stalker et al. (2006) and Martin et al. (2007) also suggest differences between genders in the efficiency of nutrient utilisation following divergent maternal nutrition during late pregnancy. However, few interactions between gender and nutrition early in life have been demonstrated for subsequent body and carcass characteristics, with these relating mainly to bone growth (Tudor et al., 1980). Within our recent studies, interactions between birth weight and gender/year cohorts were evident for carcass weight, eye muscle area, and weight of bones and retail beef at 30 months of age (Greenwood et al., 2006). However, while suggestive of interactions between sex and growth early in life, our experimental design did not allow for this interaction to be specifically tested.

\section{Interactions between growth early in life and sire-genotype}

A major objective of our research has been to determine the extent to which genotype may interact with nutrition early in life to influence subsequent growth, carcass, yield and beef-quality characteristics. To achieve this objective, our research included offspring of Piedmontese (a high muscling, high-birth-weight breed homozygous for a non-functional mutation in myostatin) and Wagyu (a high marbling and lower birth weight breed) bulls. Perhaps surprisingly, no interactions between sire-genotype and growth early in life were evident for any production parameters reported here or presented by Greenwood et al. (2006).

\section{Conclusions}

Severe, chronic growth retardation of cattle early in life is associated with reduced growth potential, resulting in smaller animals at any given age. The capacity for long-term compensatory growth diminishes as the age of onset of severe nutritional restriction resulting in prolonged growth retardation declines, such that more-extreme intrauterine growth retardation can result in slower growth throughout postnatal life. However, within the normal limits of beef production systems, neither restricted growth in utero nor from birth to weaning influences the efficiency of nutrient utilisation later in life.
Retail yield from cattle severely restricted in growth during pregnancy or from birth to weaning is reduced compared with cattle well grown early in life, when compared at the same age later in life. However, retail yield and carcass composition of low- and high-birth-weight calves are similar when compared at the same carcass weight.

At equivalent carcass weights, cattle that are grown slowly from birth to weaning have carcasses of similar or leaner composition than those grown rapidly. However, there is evidence to suggest that if high energy, concentrate feed is provided following severe growth restriction from birth to weaning, then at equivalent weights post weaning the slowly growing, small weaners may be fatter than their well-grown counterparts.

Restricted prenatal and pre-weaning nutrition and growth do not adversely affect measures of beef quality including shear force, compression, cooking loss and colour. Similarly, bovine myofibre characteristics are little affected in the long term by growth in utero or from birth to weaning, despite specific myofibre-type-related effects at birth and weaning, respectively.

Hence, economic benefits resulting from adequate maternal nutrition, especially during pregnancy, to optimise growth of offspring to market weights are primarily due to advantages in carcass weight and retail beef yield at a given age, reduced feed costs to reach a given market weight, stocking rates and subsequent reproductive rates of breeding cows, but not due to differences in beef-quality characteristics (Alford et al., 2007).

Interactions were not evident between prenatal and preweaning growth for subsequent growth, efficiency, carcass, yield and beef-quality characteristics, within our pasturebased production systems. Interactions between genotype and nutrition early in life studied using offspring of Piedmontese (a high muscling, higher birth weight breed, homozygous for a mutation that produces non-functional myostatin) and Wagyu (a high marbling, lower birth weight breed) sires mated to Hereford cows were not evident for any growth, efficiency, carcass, yield and beef-quality parameters.

We propose that within pasture-based production systems for beef cattle, the plasticity of the carcass tissues, particularly of muscle, allows animals that are growthretarded early in life to attain normal carcass composition at equivalent weights in the long term, albeit at older ages. This may well relate to regulation of nutrient intake to a level appropriate for the size and lean tissue growth capacity of the animal, coupled with the capacity of the myosatellite cell population to generate myonuclei in support of muscle growth over a prolonged recovery period, as discussed previously (Greenwood et al., 1998, 1999 and 2000a). However, the availability of feed and quality of nutrition during recovery from severe growth retardation early in life may be important in determining the subsequent composition of young, light-weight cattle relative to their heavier counterparts. 
Finally, it needs to be emphasised that long-term consequences of more specific, acute environmental influences during specific stages of embryonic, foetal and neonatal calf development remain to be determined. This need for further research extends to consequences of nutrition and growth early in life for subsequent reproductive performance, which has been recently shown to be affected in heifers by nutrition of their dams during late pregnancy (Martin et al., 2007), although neither reproductive or lactational performance were affected by birth weight (Swali and Wathes, 2006).

\section{Acknowledgements}

The contributions of Ms Helen Hearnshaw, Dr David Hennessy and Professor John Thompson in the conduct of research on consequences of growth and nutrition during early life of cattle described herein are most gratefully acknowledged. The financial and in-kind support of the Cooperative Research Centre for Cattle and Beef Quality, NSW Department of Primary Industries, CSIRO Livestock Industries and the University of New England is gratefully acknowledged. We also acknowledge the considerable efforts of research, technical and/or farm staff of NSW Department of Primary Industries Agricultural Research and Advisory Stations at Grafton and Glenn Innes and its Beef Industry Centre of Excellence in Armidale, at the Beef CRC 'Tullimba' Feedlot, at CSIRO Livestock Industries, Queensland Bioscience Precinct, St Lucia, and at the University of New England Meat Science Complex, in the conduct of the Beef CRC research described in this review.

\section{References}

Alford AR, Cafe LM, Greenwood PL and Griffith GR 2007. The economic effects of early-life nutritional constraints in crossbred cattle bred on the NSW North Coast. Economic Research Report no. 33. NSW Department of Primary Industries, Armidale, NSW, Australia.

Allden WG 1970. The effects of nutritional deprivation on the subsequent productivity of sheep and cattle. Nutrition Abstracts and Reviews 40, 1167-1184.

Andreoli KM, Minton JE, Spire MF and Schalles RR 1988. Influence of prepartum exposure of beef heifers to winter weather on concentrations of plasma energy-yielding substrates, serum hormones and birth weight of calves. Theriogenology 29, 631-642.

Anthony RV, Bellows RA, Short RE, Staigmiller RB, Kaltenbach CC and Dunn TG 1986a. Fetal growth of beef calves. I. Effects of prepartum dietary crude protein on birth weight, blood metabolites and steroid hormone concentrations. Journal of Animal Science 62, 1363-1374.

Anthony RV, Bellows RA, Short RE, Staigmiller RB, Kaltenbach CC and Dunn TG $1986 \mathrm{~b}$. Fetal growth of beef calves. II. Effects of sire on prenatal development of the calf and related placental characteristics. Journal of Animal Science 62, 1375-1387.

Bell AW, Wilkening RB and Meschia G 1987. Some aspects of placental function in chronically heat-stressed ewes. Journal of Developmental Physiology 9, 17-29.

Bell AW, Greenwood PL and Ehrhardt RA 2005. Regulation of metabolism and growth during prenatal life. In Biology of metabolism in growing animals (ed. DG Burrin and HJ Mersmann), pp. 3-34. Elsevier, Amsterdam, Holland.

Bell AW 2006. Prenatal programming of postnatal productivity and health of livestock: a brief review. Australian Journal of Experimental Agriculture 46, 725-732.
Bellows RA and Short RE 1978. Effects of precalving feed level on birth weight, calving difficulty and subsequent fertility. Journal of Animal Science 46 , 1522-1528.

Bellows RA, Carr JB, Patterson DJ, Thomas O0, Killen JH and Milmine WL 1978. Effects of ration protein content on dystocia and reproduction in beef heifers. Proceedings of the Western Section of the American Society of Animal Science 29, 263-265.

Bellows RA, Short RE and Richardson GV 1982. Effects of sire, age of dam and gestation feed level on dystocia and postpartum reproduction. Journal of Animal Science 55, 18-27.

Berge P 1991. Long-term effects of feeding during calfhood on subsequent performance of beef cattle (a review). Livestock Production Science 28, 179-201.

Cafe LM, Hearnshaw H, Hennessy DW and Greenwood PL 2006a. Growth and carcass characteristics at heavy market weights of Wagyu-sired steers following slow or rapid growth to weaning. Australian Journal of Experimental Agriculture 46, 951-955.

Cafe LM, Hennessy DW, Hearnshaw H, Morris SG and Greenwood PL 2006b. Influences of nutrition during pregnancy and lactation on birth weights and growth to weaning of calves sired by Piedmontese or Wagyu bulls. Australian Journal of Experimental Agriculture 46, 245-255.

Clarke AJ, Cummins LJ, Wilkins JF, Hennessy DW, Andrews CM and Makings BJ 1994. Post weaning growth of twin cattle born at Hamilton and Grafton. Proceedings of the Australian Society of Animal Production 20, 34-35.

Collier RJ, Doelger SG, Head HH, Thatcher WW and Wilcox CJ 1982. Effect of heat stress during pregnancy on maternal hormone concentrations, calf birth weight and postpartum milk yield of Holstein cows. Journal of Animal Science 54, 309-319.

Cooper K, Morris ST and McCutcheon SN 1998. Effect of maternal nutrition during early and mid-gestation on fetal growth. Proceedings of the New Zealand Society of Animal Production 58, 175-177.

Corah LR, Dunn TG and Kaltenbach CC 1975. Influence of prepartum nutrition on the reproductive performance of beef females and the performance of their progeny. Journal of Animal Science 41, 819-824.

Cummins LJ 1994. Beef cattle twinning. Proceedings of the Australian Society of Animal Production 20, 27-36.

De Rose EP and Wilton JW 1991. Productivity and profitability of twin births in beef cattle. Journal of Animal Science 69, 3085-3093.

Dunn TG, Ingalls JE, Zimmerman DR and Wiltbank JN 1969. Reproductive performance of 2-year-old Hereford and Angus heifers as influenced by preand post-calving energy intake. Journal of Animal Science 29, 719-726.

Echternkamp SE 1993. Relationship between placental development and calf birth weight in beef cattle. Animal Reproduction Science 32, 1-13.

Ehrhardt RA and Bell AW 1995. Growth and metabolism of the ovine placenta during mid gestation. Placenta 16, 727-741.

Ferrell CL, Garrett WN and Hinman N 1976. Growth, development and composition of the udder and gravid uterus of beef heifers during pregnancy. Journal of Animal Science 42, 1477-1489.

Ferrell CL, Ford SP, Prior RL and Christenson RK 1983. Blood flow, steroid secretion and nutrient uptake of the gravid bovine uterus and foetus. Journal of Animal Science 56, 656-667.

Ferrell CL 1989. Placental regulation of fetal growth. In Animal growth regulation (ed. DR Campion, GJ Hausman and RJ Martin), pp. 1-19. Plenum Press, New York, USA.

Ferrell CL 1991. Maternal and foetal influences on uterine and conceptus development in the cow: I. Growth of the tissues of the gravid uterus. Journal of Animal Science 69, 1945-1953.

Freetly HC, Ferrell CL and Jenkins TG 2000. Timing of realimentation of mature cows that were feed-restricted during pregnancy influences calf birth weights and growth rates. Journal of Animal Science 78, 2790-2796.

Greenwood PL, Hunt AS, Hermanson JW and Bell AW 1998. Effects of birth weight and postnatal nutrition on neonatal sheep: I. Body growth and composition, and some aspects of energetic efficiency. Journal of Animal Science 76, 2354-2367.

Greenwood PL, Slepetis R, Hermanson JW and Bell AW 1999. Intrauterine growth retardation is associated with reduced cell cycle activity, but not myofibre number, in ovine fetal muscle. Reproduction Fertility and Development 11, 281-291. 
Greenwood PL, Hunt AS, Hermanson JW and Bell AW 2000a. Effects of birth weight and postnatal nutrition on neonatal sheep: II. Skeletal muscle growth and development. Journal of Animal Science 78, 50-61.

Greenwood PL, Slepetis RM and Bell AW 2000b. Influences on fetal and placental weights during mid and late gestation in prolific ewes well nourished throughout pregnancy. Reproduction Fertility and Development 12, 149-156. Greenwood PL, Hunt AS, Slepetis RM, Finnerty KD, Alston C, Beermann DH and Bell AW 2002a. Effects of birth weight and postnatal nutrition on neonatal sheep: III. Regulation of energy metabolism. Journal of Animal Science 80 2850-2861.

Greenwood PL, Wolcott M, Hearnshaw H, Hennessy DW, Morris SG and Harper GS 2002b. Fetal growth capacity influences nutritional status of Hereford cows during pregnancy. Animal Production in Australia 24, 304.

Greenwood PL and Bell AW 2003. Consequences of intra-uterine growth retardation for postnatal growth, metabolism and pathophysiology. Reproduction 61(Suppl.), 195-206.

Greenwood PL, Hearnshaw H, Kelly G and Hennessy DW 2004. Nutrition of Wagyu- and Piedmontese-sired foetuses alters newborn longissimus muscle cellular characteristics. Journal of Animal Science 82(Suppl. 1), 251.

Greenwood PL, Cafe LM, Hearnshaw H and Hennessy DW 2005. Consequences of nutrition and growth retardation early in life for growth and composition of cattle and eating quality of beef. Recent Advances in Animal Nutrition in Australia 15, 183-195.

Greenwood PL, Cafe LM, Hearnshaw H, Hennessy DW, Thompson JM and Morris SG 2006. Long-term consequences of birth weight and growth to weaning for carcass, yield and beef quality characteristics of Piedmonteseand Wagyu-sired cattle. Australian Journal of Experimental Agriculture 46, 257-269.

Gregory KE, Echternkamp SE, Dickerson GE, Cundiff LV, Koch RM and Van Vleck LD 1990. Twinning in cattle: III. Effects of twinning on dystocia reproductive traits, calf survival, calf growth and cow productivity. Journal of Animal Science 68, 3133-3144.

Gregory KE, Echternkamp SE and Cundiff LV 1996. Effects of twinning on dystocia, calf survival, calf growth, carcass traits and cow productivity. Journal of Animal Science 74, 1223-1233.

Hafez ESE and Rajakoski E 1964. Placental and fetal development during multiple bovine pregnancy. Anatomical Record 150, 303-316.

Hearnshaw H 1997. Effect of pre-weaning nutrition on post-weaning growth carcase and meat quality traits. In Growth and development of cattle. Proceedings of the growth and development workshop (ed. DW Hennessy, SR McLennan and VH Oddy), pp. 59-67. Cooperative Research Centre for Cattle and Beef Quality, Armidale, Australia.

Hennessy DW and Wilkins JF 1997. The nutrition of single and twin suckled calves and their growth-12 months post weaning. In Growth and development of cattle. Proceedings of the growth and development workshop (ed. DW Hennessy, SR McLennan and VH Oddy), pp. 45-47. Cooperative Research Centre for Cattle and Beef Quality, Armidale, Australia.

Hennessy DW, Morris SG and Allingham PG 2001. Improving the pre-weaning nutrition of calves by supplementation of the cow and/or the calf while grazing low quality pastures 2 . Calf growth, carcass yield and eating quality. Australian Journal of Experimental Agriculture 41, 715-724.

Hennessy DW, Hearnshaw H, Greenwood PL, Harper GS and Morris SG 2002. The effects of low or high quality pastures on the live weight of cows at calving and on birth weight of calves sired by Wagyu or Piedmontese. Animal Production in Australia 24, 311.

Hennessy DW and Morris SG 2003. Effect of a preweaning growth restriction on the subsequent growth and meat quality of yearling steers and heifers. Australian Journal of Experimental Agriculture 43, 335-341.

Hennessy DW and Arthur PF 2004. The effect of preweaning growth restriction on the feed intake and efficiency of cattle on a grain-based diet before slaughter. Australian Journal of Experimental Agriculture 44, 483-488.

Hight GK 1966. The effects of undernutrition in late pregnancy on beef cattle production. New Zealand Journal of Agricultural Research 9, 479-490.

Hight GK 1968a. Plane of nutrition effects in late pregnancy and lactation on beef cows and their calves to weaning. New Zealand Journal of Agricultural Research 11, 71-84.

Hight GK 1968b. A comparison of the effects of three nutritional levels in late pregnancy on beef cows and their calves. New Zealand Journal of Agricultural Research 11, 477-486.
Hodge PB and Rowan KJ 1970. Effect of varying the plane of nutrition on the calving performance of Hereford heifers. Proceedings of the Australian Society of Animal Production 8, 410-413.

Hodge PB, Beasley RC and Stokoe J 1976. Effect of three levels of grazing nutrition upon calving and subsequent performance in Hereford heifers. Proceedings of the Australian Society of Animal Production 11, 245-248.

Holland MD and Odde KG 1992. Factors affecting calf birth weight: a review. Theriogenology 38, 769-798.

Joubert DM and Hammond J 1958. A cross-breeding experiment with cattle, with special reference to maternal effect in South Devon-Dexter crosses. Journal of Agricultural Science 51, 325-341.

Kroker GA and Cummins $\amalg$ 1979. The effect of nutritional restriction on Hereford heifers in late pregnancy. Australian Veterinary Journal 55, 467-474.

Laster DB 1974. Factors affecting pelvic size and dystocia in cattle. Journal of Animal Science 38, 496-503.

Lehnert SA, Byrne KA, Reverter A, Nattrass GS, Greenwood PL, Wang YH, Hudson NJ and Harper GS 2006. Gene expression profiling of bovine skeletal muscle in response to and recovery from chronic and severe undernutrition. Journal of Animal Science 84, 3239-3250.

Loxton ID 1997. Influence of growth pattern, nutrition and compensatory growth on meat quality in Northern Australia. In Growth and development of cattle. Proceedings of the Growth and Development Workshop Cooperative Research Centre for Cattle and Beef Quality (ed. DW Hennessy, SR McLennan and VH Oddy), pp. 69-80. Armidale, Australia.

Lyne AG 1960. Pre-natal growth of cattle. Proceedings of the Australian Society of Animal Production 3, 153-161.

Martin JL, Vonnahme KA, Adams DC, Lardy GP and Funston RN 2007. Effects of dam nutrition on growth and reproductive performance of heifer calves. Journal of Animal Science 85, 841-847.

Palsson H 1955. Conformation and body composition. In Progress in physiology of farm animals (ed. J Hammond), pp. 430-542. Butterworths, London, UK.

Perry D, Shorthose WR, Ferguson DM and Thompson JM 2001. Methods used in the CRC programme for the determination of carcass yield and beef quality. Australian Journal of Experimental Agriculture 41, 953-957.

Perry VEA, Norman ST, Owen JA, Daniel RCW and Phillips N 1999. Low dietary protein during early pregnancy alters bovine placental development. Animal Reproduction Science 55, 13-21.

Perry VEA, Norman ST, Daniel RCW, Owens PC, Grant P and Doogan VJ 2002. Insulin-like growth factor levels during pregnancy in the cow are affected by protein supplementation in the diet. Animal Reproduction Science 72, 1-10.

Prior RL and Laster DB 1979. Development of the bovine fetus. Journal of Animal Science 48, 1546-1553.

Purchas RW, Burnham DL and Morris ST 2002. Effects of growth potential and growth path on tenderness of beef longissimus muscle from bulls and steers. Journal of Animal Science 80, 3211-3221.

Rasby RJ, Wettermann RP, Geisert RD, Rice LE and Wallace CR 1990. Nutrition, body condition and reproduction in beef cows: fetal and placental development, and estrogens and progesterone in plasma. Journal of Animal Science 68, 4267-4276.

Reynolds LP, Ferrell CL and Nienaber JA 1985. Effects of chronic environmental heat stress on blood flow and nutrient uptake of the gravid bovine uterus and foetus. Journal of Agricultural Science 104, 289-297.

Reynolds LP, Ferrell CL, Robertson DA and Ford SP 1986. Metabolism of the gravid uterus, foetus and utero-placenta at several stages of gestation in cows. Journal of Agricultural Science 106, 437-444.

Rhoads RP, Greenwood PL, Bell AW and Boisclair YR 2000a. Organization and regulation of the gene encoding the sheep acid-labile subunit of the $150 \mathrm{kDa}$ binding protein complex. Endocrinology 141, 1425-1433.

Rhoads RP, Greenwood PL, Bell AW and Boisclair YR 2000b. Nutritional regulation of the genes encoding the acid-labile subunit and other components of the circulating insulin-like growth factor system in the sheep. Journal of Animal Science 78, 2681-2689.

Ryley JW and Gartner RJW 1962. Drought feeding studies with cattle. 7. The use of sorghum grain as a drought fodder for cattle in late pregnancy and early lactation. Queensland Journal of Agricultural Science 19, 309-330.

Stalker LA, Adams DC, Klopfenstein TJ, Feuz DM and Funston RN 2006. Effects of pre- and postpartum nutrition on reproduction in spring calving cows and calf feedlot performance. Journal of Animal Science 84, 2582-2589. 
Swali A and Wathes DC 2006. Influence of the dam and sire on size at birth and subsequent growth, milk production and fertility in dairy heifers. Theriogenology 66, 1173-1184.

Symonds ME, Stephenson T, Gardner DS and Budge H 2007. Long-term effects of nutritional programming of the embryo and fetus: mechanisms and critical windows. Reproduction Fertility and Development 19, 53-63.

Thompson GE, Bassett JM, Samson DE and Slee J 1982. The effects of cold exposure of pregnant sheep on foetal plasma nutrients, hormones and birth weight. British Journal of Nutrition 48, 59-64.

Tudor GD 1972. The effect of pre- and post-natal nutrition on the growth of beef cattle. I. The effect of nutrition and parity of the dam on calf birth weight. Australian Journal of Agricultural Research 23, 389-395.

Tudor GD and O'Rourke PK 1980. The effect of pre- and post-natal nutrition on the growth of beef cattle. II. The effect of severe restriction in early postnatal life on growth and feed efficiency during recovery. Australian Journal of Agricultural Research 31, 179-189.

Tudor GD, Utting DW and O'Rourke PK 1980. The effect of pre- and post-natal nutrition on the growth of beef cattle. III. The effect of severe restriction in early postnatal life on the development of the body components and chemical composition. Australian Journal of Agricultural Research 31, 191-204.

Wallace JM, Aitken RP and Cheyne MA 1996. Nutrition partitioning and foetal growth in rapidly growing adolescent ewes. Journal of Reproduction and Fertility 107, 183-190.
Wallace JM, Bourke DA and Aitken RP 1999. Nutrition and foetal growth: paradoxical effects in the overnourished adolescent sheep. Journal of Reproduction and Fertility 54(Suppl.), 385-399.

Warner RG and Flatt WP 1965. Anatomical developments of the ruminant stomach. In Physiology and digestion in the ruminant (ed. RW Doherty, RS Allen, W Buroughs, NL Jacobsen and AD McGilliard), pp. 24-38. Butterworths, Washington, DC, USA.

Wilkins JF, Hennessy DW and Farquharson RJ 1994. Twinning in beef cattle. Roles of nutrition and early weaning in herds of high calving rate. Final report to Meat Research Corporation. NSW Agriculture, Grafton, Australia.

Wiltbank JN, Bond J, Warwick EJ, Davis RE, Cook AC, Reynolds WL and Hazen MW 1965. Influence of total feed and protein intake on reproductive performance of the beef female through second calving. Technical bulletin no. 1314. USDA, Washington, DC, USA.

Winters LM, Green WW and Comstock RE 1942. Prenatal development of the bovine. Technical bulletin no. 151. University of Minnesota Agricultural Experiment Station, Saint Paul, MN, USA.

Zhang WC, Nakao T, Moriyoshi M, Nakada K, Ohtaki T, Ribadu AY and Tanaka Y 1999. The relationship between plasma oestrone sulphate concentrations in pregnant dairy cattle and calf birth weight, calf viability, placental weight and placental expulsion. Animal Reproduction Science 54, 169-178. 